\title{
Deconstructing Laundry: Gendered Technologies and the Reluctant Redesign of Household Labor
}

\author{
Constance L. Shehan ${ }^{1}$ and Amanda B. Moras
}

\begin{abstract}
In this paper we examine the ways in which technological innovations have entered the home through the process of laundry. We take a brief look at the history of laundry technology, examining the costs of locating laundry in the private sphere and discussing alternatives. We highlight the links between laundry technology and ideologies about "women's place."
\end{abstract}

Key Words: Household labor, gender and technology, women's employment, family laundry

${ }^{1}$ Constance Shehan is Professor, Department of Sociology, University of Florida, P.O. Box 117330, Gainesville, FL 32611-7330 (352) 392-0265, extension 254. Electronic mail may be sent to shehan@soc.ufl.edu.

In the opening decade of the $21^{\text {st }}$ century, the performance of household tasks remains, for the most part, labor intensive and relegated to the realm of "women's work," consuming a great deal of women's time and energy. Research has long shown that the introduction of technology into the home through so-called "labor saving devices" did not significantly reduce women's time in housework. It simply changed the amount of time men and children allocated to housework and changed the way in which women performed household tasks (Cowan, 1983). 
In this paper, we examine the technology women use to do the family "wash." Our broader purpose is to call attention to the ways in which the availability of domestic technology and the demands of the economy intersect to construct ideas about women's place inside and outside the home and family. We briefly review the history of laundry technology, following its use in the establishment of the commercial laundry industry, and link it broadly to historical trends in women's labor force participation by class and race. We trace the sales of household washing machines from the early decades of the $20^{\text {th }}$ century, noting the competition between the establishment of the commercial laundry industry and the market forces that attempted to put washing machines in every home. We briefly examine the ideologies that developed over the past 100 years to justify the development of the home appliance industry, in spite of the considerable financial and environmental costs associated with the proliferation of domestic laundry equipment. Ideologies about "women's place" have alternately been used to dampen the proliferation of innovations in laundry technology or to make it acceptable for women to look to technological innovations, first to improve the quality and efficiency of their labor and later to reduce the time they spend doing family laundry. We conclude with observations about countervailing forces that may do what earlier processes of industrialization failed to do - move the tasks associated with laundry out of the home permanently.

\section{A Brief Chronology of Laundry Technology}

Laundry is a relatively recent addition to the domestic work process. It didn't become a weekly chore until the $19^{\text {th }}$ century, largely because the types of clothing that were worn in preindustrial times (i.e., those made of felt, leather, wool, linen, and/or alpaca) could not be laundered. Instead, they were shaken or brushed to remove dirt. When cotton replaced linen and wool as the fabric of choice for clothing, laundry became a major component of women's labor in the home (Cowan, 1983). As the 
$19^{\text {th }}$ century progressed, laundry became an increasingly more important household task. During this period of time, however, laundry was largely a non-mechanical and quite arduous process. Typically, women allocated at least a full day of labor to laundry. They were unable to do all of the work by themselves. Water had to be carried to the laundry site where it was heated over a fire. Soap was made by women out of lye and animal fat, a process that proved toxic to their skin. Wash boards became the primary method of getting dirt from clothes. Wet clothes and linens were hung outside to dry, no matter what the weather conditions. "Even the most pared-down version of the laundry routine demanded an enormous amount of hard, hot, and heavy work" (Cowan, 1983, p. 108).

There were many experiments with domestic washing machines. Table 1 presents a chronology of laundry technology since 1800. In the sections that follow we highlight some of the most important developments and attempt to put them into the social and economic context of the time in which they appeared. Although we focus primarily on washing machines, we recognize that parallel developments in other steps of the laundry process (e.g., drying and pressing clothes), in the types of cleaning agents that were available (e.g., homemade soap composed of lye and animal fats versus detergents that were developed during World War I) and in the types of fabrics used for clothing and household linens (i.e., the introduction of "permanent press") were just as important in changing the amount and type of labor associated with the family wash.

\section{Important Developments in Laundry Technology in the $19^{\text {th }}$ Century}

The first U.S. patent for a washing machine was filed in 1805 (Hardyment, 1988). Over the course of the $19^{\text {th }}$ century, more than two thousand U.S. patents for washing machines were filed, addressing various aspects of the laundry process (i.e., tools 
to approximate the action of human knuckles in rubbing dirt from clothes and mechanical devices to wring water from wet clothes).

Table 1: A Brief Chronology of Laundry Technology Since 1800

\section{$19^{\text {th }}$ Century Highlights}

1805: $\quad$ First US patent for washing machine filed

1830s: Commercial laundries established

1869: Vertical axis, gyrator-type washing machine invented;

1882: $\quad$ Patent for electric iron granted

1870-1910: Proliferation of commercial laundries

\section{$20^{\text {th }}$ and $21^{\text {st }}$ Century Highlights}

1908: $\quad$ Small electric motor invented

1915: First electric clothes washer

1916: Detergent discovered by German scientists

1918: Rinso, first soap powder, enters market

1920s: Commercial laundries reach peak; serious marketing of washing machines for homes began

1926: $\quad 900,000$ washing machines sold

1930s: Coin-operated Laundromats popular; used to teach

1939: $\quad$ women how to use machines; buy for

1946: $\quad$ Tide detergent enters market

Post-WWII: Development of suburbs; manufacturers' goal: washing machine in every home

1961: Pampers enter market

1964: Permanent press fabric/clothing introduced

1994: $\quad$ Microwave dryer introduced

2000: Dryel (dry cleaning at home, in clothes dryers)

2000: Federal legislation about environmental standards for washing machines

2002: $\quad 14,500,000$ washer/dryer units sold in US (2002)

Sources: Cowan (1983); Lupton (1993); Panati (1987); Shapiro (1998).

US News \& World Report (1998). 
Deconstructing Laundry 43

\section{Washerwomen and Laundresses}

Laundry in the pre-mechanized years required more than one person. But always at the center of the process was the woman householder. Helpers included unpaid female family members or boarders, paid "washer women" who worked at the home where the laundry was being done, and unpaid male family members who might help in chopping and carrying the wood used to build the fires that would heat the wash water and carrying the buckets of water used in the wash.

Because laundry historically was regarded as "women's" work, $19^{\text {th }}$ century men who were unmarried and/or lived alone were forced to find alternative ways to have their clothes washed. A commercial laundry industry began to develop in the 1830s to serve unmarried men who lived and worked in U.S. mining towns and seaports (Lupton, 1993). It wasn't until the 1890s that commercial laundries began to be used for "family washes."

The first articles of clothing families sent out to commercial laundries were men's shirts, suits, and collars. Between 1870 and 1910, it became common for middle-class families to send out their laundry to commercial laundries. In each decade of this period, the number of women employed in laundries increased substantially. By 1900, most families had at least some of their laundry done by hired "washer women" or commercial laundries. The majority of women who washed clothes for others were immigrants and/or people of color, as institutionalized racism, segregation, and lack of opportunity often made this the only viable option for employment (Landry, 2000, pp. 48-49). Commercial laundries relied on racist advertising campaigns in which they claimed to offer services that were superior to those of "the ignorant washerwomen" -- typically black women -- and the "suspicious practices" of the "hand laundries" -- typically owned and run by Chinese Americans (Lupton, 1993, p. 16). Some of the women who earned wages by doing other people's laundry worked 
in their employers' homes; others took laundry into their own homes. The latter arrangement was preferred by the workers because it allowed them to fit the paid work into their family schedule and gave them some autonomy.

\section{Commercial Laundries}

Commercial laundries, of course, had other major clientele, including hospitals, hotels, and restaurants. Their success acted as the impetus for the development of mechanical devices that could speed up the process and reduce the costs of doing a large volume of clothing and linens. Many of the laundry appliances that eventually appeared in American homes grew out of this industry.

Commercial laundries had both advocates and opponents. Catherine Beecher and Harriet Beecher Stowe argued that since laundry was the most arduous, uncreative, and yet necessary part of a woman's domestic work, "it would simplify the burdens of the American housekeeper to have washing and ironing day expunged from her calendar." Detractors, on the other hand, argued that commercial laundries were expensive and often resulted in damaged or lost clothing (Cowan, 1983, p. 107).

The commercial laundry industry declined during the Great Depression of the 1930s. In the early post World War II years, it increased briefly but then went into a decline from which it has never recovered, due to the heavy marketing of domestic washing machines (Cowan, 1983). As Helen and Robert Lynd (1929) pointed out in their classic study of Middletown, pushing laundry back into private homes reinforced the institutionalized divisions of labor and resulted in the increased isolation of households:

This is an example of the way in which a useful invention (i.e., washing machines) vigorously pushed on the market by effective advertising may serve to slow up a secular trend. The heavy investment by the individual family in an 
electric washing machine ... tends to perpetuate a questionable institutional setup, whereby many individual homes repeat common tasks day after day in isolated units - by forcing back into the individual home a process that was following belatedly the trend in industry toward centralized operation (p. 107).

\section{Important Developments in Laundry Technology in the $20^{\text {th }}$ Century}

The introduction of electric power in urban areas in the early 1900s, along with the invention of the small electric motor, made it feasible to manufacture and market domestic washing machines. Serious marketing of these appliances to individual home owners began in the 1920s, which, not coincidentally, was the peak of the commercial laundry industry. By 1927, Maytag had sold one million washing machines. The early electrically powered machines consisted of tubs equipped with revolving agitators which circulated soapy water through fabric. When the agitation cycle was complete, the clothes had to be passed through an attached wringer by hand. Machines that weren't permanently plumbed had to be filled and drained manually. Fully automated washing machines - which filled and drained water automatically and spun clothes "dry" to reduce the amount of water left after rinsing -- did not become available until the late 1930s. But until electric power became available in the early $20^{\text {th }}$ century, washing machines were not widely used in private homes (Lupton, 1993).

The early marketing of electric washing machines met with some resistance from homemakers who believed mechanical devices could not be trusted to do the wash as well as their own hands could do it. In response, coin-operated Laundromats were introduced by manufacturers in urban areas in the 1930s to teach women how to use the machines and to develop trust in them. Those who purchased these machines typically used them to replace hired laundresses. As a result of purchasing washing 
machines, however, housewives took over the entire responsibility for doing their family's laundry. Although the physical labor of laundry was lessened somewhat by the machines, the actual time housewives allocated to their family laundry increased (Hardyment, 1988). In many rural areas that didn't have electricity until later in the $20^{\text {th }}$ century -- and among those who couldn't afford the price of washing machines -- many aspects of $19^{\text {th }}$ century laundry processes continued to be used.

After World War II, the manufacture and marketing of domestic washing machines increased substantially, as the federal government subsidized the construction of highways and facilitated the growth of suburbs. As domestic ownership of electric washing machines increased, the popularity of commercial laundry services among American families declined. But the development of Laundromats in urban areas in the 1930s allowed families without access to private laundry facilities to wash their clothes mechanically.

The sales of domestic laundry appliances increased dramatically in the $1950 \mathrm{~s}$, with the increase continuing to the present. In 2003 alone, nearly 15 million laundry appliances were sold in the U.S. Ownership of home appliances is, of course, a function of household income. The percent of U.S. households that have a washing machine and a clothes dryer differs from 45 percent among the lowest income level to 92 percent among the highest income level (Energy Information Administration, 2001). Furthermore, use of coin-operated Laundromats seems to have become a class stigmatizing enterprise and is costly over a long period of time, both in terms of money and time (Shehan, 2006).

\section{U.S. Women's Labor Force Participation Patterns, 1800 - 2000}

An examination of the use of household technology would not be complete without a corresponding consideration of women's 
patterns of paid employment. Here we briefly summarize shifts in the extent and types of paid employment of women over the past 150 years. We give special attention to the employment of women in domestic and personal service, recognizing the important differences by race and national origin. ${ }^{1}$

It is well-documented, of course, that the labor of young, single, native born women allowed the U.S. to industrialize after the end of the Revolutionary War. The expansion of the U.S. economy in the middle decades of the $19^{\text {th }}$ century, however, could not be met by this group of workers; huge numbers of immigrants, primarily from Europe in the first great wave of immigration began to fill the demand for labor in factories. Native born whitewomen were largely pushed out of these jobs. By the latter decades of the $19^{\text {th }}$ century, an ideology of "idleness" for middle and upper middle class married women developed. African American women operated under a system of involuntary servitude during much of the $19^{\text {th }}$ century. After emancipation, many continued in farm work. Those who sought employment off farms were largely confined to work as domestic workers in the homes of more affluent white families (Degler, 1980).

By 1870 , over half of the female work force was employed in the category of domestic and personal service. The majority of women employed in this type of work were African Americans and European immigrants. Between 1870 and 1910, the proportion of women employed as domestic workers dropped to 20 percent overall, but the percentage of women of color employed in this type of work actually increased to 46 percent in 1920. Domestic service continued to be a major source of employment for African American women well into the $20^{\text {th }}$ century, however. By 1940, 60 percent of the African American women in the labor force were employed as domestic workers (Palmer, 1984). In the late 1930s, a study by Fortune magazine reported that "70 percent of the rich, 42 percent of the upper middle class, 14 percent of the lower middle class, and 6 percent of the poor" claimed to have hired 
domestic help (cited in Palmer, 1984). In 1940, 20 percent of all employed women were in domestic servants. Half of these women were African American or Latina (Kessler-Harris, 1982).

World War II brought an unprecedented number of women into the U.S. work force. Many of the women were from demographic groups that had not worked in large numbers previously (i.e., married white women with children). During the 1950s, the number of two-income families began what would become a long-term increase. Historians attribute this to the rise of consumerism. As Kessler-Harris (1983: 302) argued, "Homes and car, refrigerators and washing machines, telephones and multiple televisions required higher incomes." Economic changes over the second half of the $20^{\mathrm{th}}$ century continued to push and pull large numbers of American women into the labor force. By the opening years of the $21^{\text {st }}$ century, nearly 63 million women (almost $61 \%$ aged 18 and older) were employed or looking for employment (U.S. Bureau of Labor Statistics, 2001).

\section{The Costs of Having a Washing Machine in Every Home}

Contemporary Americans wash about 35 billion loads of laundry each year, cleaning 100 million tons of clothing and linen. The associated financial costs exceed four billion dollars every year (Mogelansky, 1996). A large part of the financial investment in laundry comes from purchase and repair of various laundry appliances. In a 2005 product test, Consumer Reports (2005) found that the price of washing machines ranged from roughly $\$ 300$ to $\$ 1500$.

Laundry continues to require a significant amount of women's time each week. Those aged 18 to 50 spend over 18 minutes per day, on average, doing laundry. Those with washing machines in their homes spend almost twice as much time doing laundry as those who don't have washing machines. Women

spend between 3 to 7 times as many hours in these tasks than do 
men, who do only about 20 percent of the laundry (Robinson \& Milkie, 1997).

In addition to the vast expenditures of time and money spent doing laundry in private homes by family members, there are also considerable environmental costs. The average American household uses 13,000 gallons of water per year doing laundry. This type of water consumption (which constitutes 22 percent of domestic use) is second only to toilet usage (U.S, News and World Report, 2000). The U. S. Department of Energy is phasing in stricter standards for water use by residential washing machines that started in 2004 and will continue through 2007.

\section{Signs of Change in Laundry Work}

There are indications that changes are underway in the family labor processes through which laundry is performed. The first involves an advertising campaign ostensibly designed to "shame" men into doing more laundry. In 2003, the General Electric Company launched a contest called "Ludicrous Laundry Stories" to invite women to submit outrageous stories of men's ineptness at doing laundry. Concomitantly, they designated August as "National Men Do Laundry Month." This advertising campaign surrounded the release of a new, "high tech" washer and dryer duo designed to appeal to men, suggesting that it was not an attempt to intervene in gender inequity in household labor but to sell more appliances (General Electronic Consumer and Industrial Press Room, 2003).

A second notable change in the American way of laundry labor is the proliferation of coin-operated Laundromats that offer wash-dry-fold services and home delivery of finished laundry. Laundromats, which once were primarily found in urban areas with high rental populations, are increasingly entering suburban areas populated by home owning middle and upper middle class families. While home ownership typically includes appliance 
ownership, coin-operated Laundromats offer significant time-use benefits, insofar as a family's entire laundry can be done simultaneously through the use of multiple machines. Laundromat owners are capitalizing on the time saving appeal of their facilities by adding other services (such as clothes alteration, dry cleaning, shoe repair, and tanning booths) which can be purchased on site while the laundry is being done by the machines.

\section{Summary and Implications}

Laundry has long been one of the most hated but most necessary of all household tasks. Patents related to technological innovations related to laundry have been processed since the 1700s. Technological developments associated with the development of a commercial laundry industry from the mid-1800s to the early 1900s promised to move laundry out of the domestic realm. But an elaborate ideology developed in post World War II America that justified the transfer of laundry tasks back into private homes, allowing the production of laundry appliances, detergents, and other "support" products to fuel the domestic economy. This ideology reinforced the traditional role of women in household production. The ideology has been promoted through advertising campaigns that continue to depict laundry as the domain of women (Hoy, 1996).

Because household labor is performed primarily by women and women's time has been regarded as "cheap," there has been no compelling reason to search for technological answers to household labor problems. Now that women's time for family labor is more limited and of greater economic value due to increased paid labor force participation, technological applications are increasingly being introduced into the domestic realm.

Given the substantial financial investment required to purchase laundry appliances, the recurring costs of detergents and other cleaning products, the time involved in performing the 
auxiliary tasks associated with "automatic" washers and dryers, and the environmental/energy costs of laundry technology, however, it might be more efficient for laundry tasks to once again be moved out of individual households and into commercial/communal laundry facilities. The development of commercial laundries could provide vital space for the growth of local businesses and paid domestic work. Of course, this movement would cost the home appliance industry and the manufacturers of detergents and other auxiliary laundry products a great deal of money. Furthermore, the reassignment of this work from individual households to low paid service workers could exacerbate race and class based inequities that are common within paid reproductive labor, as disenfranchised men and women are forced to take on these jobs, which are characterized by low pay, no health benefits, and dangerous or undesirable working conditions (Romero, 1995, Parreñas, 2001, Chang, 2000, Hondagneu-Sotelo, 2001).

\section{Conclusion}

Today, doing the family laundry consumes only a fraction of the time and effort it demanded on the past. It is not only the machines and the detergents that have transformed the tasks. Changes in clothing styles have also been significant. Additionally, synthetic fabrics have made frequent washing of clothes a relatively simple matter. On the other hand, Americans typically have more clothes today and wash their clothes more frequently. As a result, managing the laundry is still a major chore, especially in families with children. The fact that family laundry remains a domestic task today rather than a commercial service industry is a significant socio-historical anomaly. If commercial laundries had become cheaper and more efficient instead of declining in the face of the mass production of small domestic machines, households could have been relieved of a considerable burden. 
The development of a communal and/or commercial laundry industry could actually reduce the burdens of laundry for a wider range of Americans than the dominant practice of private ownership of laundry appliances allows. Many low-income families are forced to use coin operated Laundromats - an expensive alternative to private ownership of washers and dryers -because the purchase of washers and dryers requires larger sums of disposable income and/or access to "credit."

Will American households continue to purchase and maintain laundry appliances in an effort to preserve existing ideas about "family" and "women's place" or will time constraints and environmental concerns finally push this household task back into the marketplace? To what extent can the remaining tasks of the "typical" American home be automated, both in terms of the logistical or mechanical possibilities and in terms of the cultural acceptability? Would the household itself - indeed, the home and "the" family - have to be redesigned in order to replace the labor of women with the actions of machines? Finally, if machines replace women's labor will gender ideologies change? The future of this area of technological innovation and adoption will say much about our willingness to redefine home and family.

\section{References}

Chang, G. (2000) Disposable domestics: Immigrant women workers in the global economy. Cambridge, MA: South End Press.

Consumer Reports (February 2005). Washer and dryer update: A new spin. pp. 42-45.

Cowan, R. S. (1983). More work for mother: The ironies of household technology from the open hearth to the microwave. New York: Basic Books. 
Degler, C. (1980). At odds: Women and the family in America from the revolution to the present. New York: Oxford University Press.

Energy Information Administration (2001). The effect of income on appliances in U.S. households. Retrieved February 16, 2006, from http://www.eia.doe.gov.

General Electric Consumer and Industrial Press Room (2003). Washers and dryers: G.E. Harmony Survey exposes great laundry divide. Retrieved February 16, 2006, from http://www.geconsumerproducts.com.

Hardyment, C. (1988). From mangle to microwave. Cambridge, MA: Polity Press.

Hondagneu-Sotelo, P. (2001) Doméstica: Immigrant workers cleaning and caring in the shadows of affluence. Berkeley, CA: University of California Press.

Hoy, S. (1996). Chasing dirt. New York: Oxford University Press.

Kessler-Harris, A. (1982). Out to work: A history of wage-earning women in the United States. New York: Oxford University Press.

Landry, B. (2000). Black working wives: Pioneers of the American family. Berkeley, CA: University of California Press.

Lupton, E. (1993). Mechanical brides: Women and machines from home to office. New York: Princeton Architectural Press.

Lynd, R. S., \& Lynd, H. M. (1929). Middletown: A study in contemporary American culture. New York: Harcourt Brace. 
Mogelansky, M. (1996, July). Dirty laundry. American Demographics.

Palmer, P. (1984). Domesticity and dirt: Housewives and domestic servants in the United States 1920-1945. Philadelphia: Temple University Press.

Panati, C. (1987). Panati's extraordinary origins of everyday things. New York: Harper \& Row.

Parreñas, R. (2001) Servant of globalization: Women, migration, and domestic work. Stanford, CA: Stanford University Press.

Robinson, J., \& Milkie, M. (1997, January). Dances with dust bunnies: Housecleaning in America. American Demographics.

Romero, M. (1995). Maid in the U.S.A. New York: Rutledge.

Shapiro, L. (1998). Household appliances. Newsweek Special issue: 2000: A New Millennium, The Power of Inventions.

Shehan, C. (2006). Watching the wash: Ethnography of a suburban laundromat. Unpublished paper.

U.S. Bureau of Labor Statistics (2001). Employment characteristics of families, Table 5. Available on-line at http;//www.bls.gov.

U.S. News \& World Report (2000, August 17-24). Special issue: The great inventions of the $20^{\text {th }}$ century: Masters of discovery.

\footnotetext{
${ }^{1}$ Readers are encouraged to consult the excellent chronology of women, work, and technology provided by Ellen Lupton, 1993, for more information.
} 